\title{
Alternativa política latinoamericana al problema del desarrollo: Hinkelammert contesta a Marcuse
}

\author{
Manuel Cuervo Sola ${ }^{1}$ y Natalia Beatriz Fischetti ${ }^{2}$
}

Recibido: 15 de mayo de 2019 . Aceptado: 24 de abril de 2019

\begin{abstract}
Resumen
En este trabajo analizamos dos propuestas filosófico-políticas críticas que reflexionaron en los años 60, acerca del problema del progreso técnico ligado al desarrollo y de las condiciones de posibilidad o factibilidad histórica de emergencia de procesos de liberación en América Latina. Para ello partimos de la premisa marcuseana de un "cierre del universo político", en tanto tesis también geopolítica, para revisarla y ponerla en discusión desde ciertos desarrollos teórico políticos latinoamericanos, entre los que destacamos aquí el de Franz Hinkelammert, cuya obra tiene características especialmente adecuadas para ponerlo en diálogo con Herbert Marcuse.
\end{abstract}

Palabras clave: pensamiento crítico - Historia de las Ideas - dependentismo - liberación - geopolítica

\section{Latin American political alternative to the problem of development: Hinkelammert responds to Marcuse}

\begin{abstract}
Summary
In this article, we analyze the critical political-philosophical proposals of the 1960s on the problem of technical progress linked to development and the conditions of possibility or historical feasibility of the emergence
\end{abstract}

\footnotetext{
1 Argentino, Doctor en Ciencias Sociales, Universidad Nacional de Cuyo. Co-director y docente de la Carrera de Ciencia Política y Administración Pública de la Universidad Nacional de Cuyo. Contacto: manuelcuervosola@gmail.com ORCID: https://orcid.org/0000-0002-1372-1726

2 Argentina, Doctora en Filosofía, Universidad Nacional de Córdoba. Investigadora asistente en el INCIHUSA CCT-CONICET Mendoza. Contacto: nfischetti@mendozaconicet.gob.ar

ORCID: https://orcid.org/0000-0001-6030-3474
} 
of liberation processes in Latin America. We start from the Marcuseana premise of a "closure of the political universe", thus also a geopolitical thesis, which is reviewed and placed into discussion from a perspective of certain Latin American developments in political theory, of which here we draw emphasis to that of Franz Hinkelammert, whose works feature characteristics that make them particularly suitable for placing into dialog with Herbert Marcuse.

Keywords: critical thinking - History of Ideas - dependentism - liberation - geopolitics

\title{
Alternativa política latino-americana ao problema do desenvolvimento: Hinkelammert responde a Marcuse
}

\begin{abstract}
Resumo
Neste artigo analisamos duas propostas críticas filosófico-políticas que ponderaram nos anos 60 sobre o problema do progresso técnico ligado ao desenvolvimento e das condições de possibilidade ou factibilidade histórica de emergência dos processos de liberação na América Latina. Para isto partimos da premissa marcuseana de um "fechamento do universo político", enquanto tese também geopolítica, para revisá-la e colocá-la em discussão a partir de certos desenvolvimentos teórico-políticos latinoamericanos, entre os quais destacamos aqui o de Franz Hinkelammert, cuja obra possui características especialmente adequadas para promover um diálogo com Herbert Marcuse.
\end{abstract}

Palavras-chave: pensamento crítico - História das Ideias - dependentismo - liberação - geopolítica

\section{Acerca del lugar de enunciación. A modo de introducción}

Este texto ha sido construido en el diálogo intersubjetivo e interdisciplinario desde formaciones académicas complementarias: la filosofía y la ciencia política, que comparten la búsqueda de un pensamiento crítico. Nos hallamos en el marco de una filosofía política crítica, que revisa históricamente las ideas acerca del imperialismo-colonialismo y el progreso técnico ligado a la cuestión del par desarrollo-subdesarrollo, desde condiciones de posibilidad o factibilidad histórica propias de Nuestra América. 
En este trabajo proponemos ampliar, desde un locus de enunciación latinoamericano, la interpretación geopolítica que realiza Marcuse a mediados de los años 60 en el segundo apartado de El hombre unidimensional, denominado "El cierre del universo político". Su lectura despertó en nosotros una serie de interrogantes históricas, políticas y filosóficas al constatar en el texto marcuseano la ausencia de referencias a Latinoamérica y sus problemáticas epocales. En pos de realizar una lectura crítica de este texto clásico, ponemos en diálogo las tesis políticas que ofrece con la producción en clave latinoamericana de Franz Hinkelammert.

Para ello asumimos la perspectiva teórico-metodológica de la Historia de las Ideas Latinoamericanas. Este enfoque considera a los discursos en sus interrelaciones con otras voces, muchas veces ocultas o silenciadas, y que conforman lo que Arturo Roig denomina el "universo discursivo", es decir, "la totalidad actual o posible de los discursos correspondientes a un determinado grupo humano en una época dada (sincrónicamente) o a lo largo de un periodo (diacrónicamente) y sobre cuya base se establece, para esa misma comunidad, el complejo mundo de la intercomunicación" (Roig 1984 5) Tal como señala Adriana Arpini (2003), el análisis del universo discursivo en un texto permite reconocer las contradicciones, conflictividades y los múltiples discursos eludidos y silenciados por el texto en cuestión.

Buscamos entonces actualizar, ante un texto clásico y de amplio reconocimiento en el ámbito académico, otras voces que, como una ausencia que grita en el propio escrito marcuseano, enunciaron en y desde el Sur, en los 60 y los primeros 70, discursos que fueron parte inherente de la creciente radicalización de los movimientos políticos latinoamericanos. Estos movimientos, muchos de los cuales emergieron con los procesos nacional-populares de los años 50 y derivaron en el Cono Sur en las décadas siguientes, en las experiencias políticas de la Unidad Popular en Chile, que arribaría a la presidencia en 1970, bajo el liderazgo de Salvador Allende; en las luchas de la resistencia peronista en Argentina, que lograría derrotar a la dictadura y efectivizar el retorno de la democracia y de Juan Domingo Perón en 1973; en el 
surgimiento del Movimiento de Liberación Nacional Tupamaros en Uruguay, entre otros.

Paralelamente tenían lugar las luchas de descolonización, cuyas coordenadas geográficas se ubican fundamentalmente en África y el Sudeste Asiático, que movilizaban la producción de discursos teóricopolíticos emergentes, por ejemplo, el de Franz Fanon. Si bien estos discursos son citados por Marcuse ${ }^{3,}$ nuestro enfoque, sin embargo, busca atender la problemática específica de América latina. Por ello, la ampliación que aquí proponemos se circunscribe a discursos latinoamericanos, asumiendo las palabras de Estela Fernández Nadal sobre esta cuestión:

Por una parte, desde fuera del campo de estudio, autodefinido como "de la subalternidad", algunos autores han señalado la no pertinencia de la trasposición de categorías elaboradas para pensar experiencias culturales propias de las ex colonias inglesas y francesas a la interpretación de nuestra realidad cultural. Esta posición se fundamenta en la apreciación de que, a diferencia de aquéllas, la mayoría de los países latinoamericanos nacieron a la vida independiente a principios del siglo XIX. Si bien a partir de entonces sufrieron la penetración de los intereses neocoloniales, primero, $y$, a fines de esa centuria y comienzos de la siguiente, imperialistas, la experiencia histórica latinoamericana posee una especificidad tal que amerita un enfoque igualmente específico (Fernández Nadal 2004).

En la consideración de un posicionamiento crítico propio, colectivo, comprometido con nuestra situación histórica y contextual particular, nos apoyamos también en la noción de "a priori antropológico" roigeana:

\footnotetext{
${ }^{3}$ Marcuse tiene como uno de sus referentes la producción de Fanon y en varios de sus escritos de la época se refiere a "Los condenados de la tierra". Cfr., por ejemplo, el Prefacio a la edición francesa de El hombre unidimensional y La tolerancia represiva.
} 
Al hablar de sujeto histórico nos referimos al sujeto empírico que se mueve dialécticamente en la realidad y que, lejos de transitar una temporalidad lineal y unívoca, avanza por oposiciones y negaciones en un constante proceso de autovaloración y autoafirmación. Ello implica la aceptación de un "a priori antropológico", [...]. Es decir una 'sujetividad' plural, un nosotros, que se juega dentro del proceso histórico de las relaciones humanas (Arpini 2003 90).

Con estas prerrogativas abordamos algunas de nuestras inquietudes acerca de la tesis que formula Marcuse en el capítulo referido, según la cual estaría ocurriendo un cierre del universo político como resultado de la expansión de la racionalidad tecnológica en el mundo que emerge con posterioridad a la Segunda Guerra Mundial. En este sentido, apelamos a lo que plantea Franz Hinkelammert para interpretar la realidad latinoamericana en esos años (1970), pensador que, al igual que Marcuse, encuentra parte de sus raíces teóricas en la primera Escuela de Frankfurt. Releemos hoy a Marcuse con las premisas de un pensamiento latinoamericano crítico y conjeturamos que, mientras en el Norte operaba un cierre del universo político con anclaje en la tecnología y su racionalidad (Fischetti 2012), en América Latina, especialmente en los países del Cono Sur, nos hallábamos en un horizonte de apertura política. El cierre, la clausura de la discusión política, tuvo lugar para nuestros países en otras coordenadas: las del terrorismo de Estado, propio de las dictaduras genocidas de mediados de los años 70.

\section{La clausura política en El hombre unidimensional: impotencia de los clivajes frente a la racionalidad tecnológica}

Marcuse, en 1964, en Estados Unidos, publica El hombre unidimensional. Como en general en toda la obra de Herbert Marcuse, nos encontramos en este segundo apartado del libro que se enfoca en la cuestión política, con la tensión dialéctica entre la perspectiva del individuo, subjetiva, psicoanalíticamente tratada, y la interpretación 
social de cuño marxiano. Ni el análisis freudiano ni el análisis desde Marx son ortodoxos. Marcuse propone una antropología dialéctica entre el trabajo y el deseo que entrecruza herramientas de la teoría crítica clásica con elementos críticos de la metapsicología freudiana (Fischetti 2015). En el cruce, en la bisagra en la que ambas perspectivas pivotan, se asienta la problemática de la tecnología en su despliegue como racionalidad tecnológica. La racionalidad tecnológica, eficiente y productiva, se extiende a nivel del individuo, y también socialmente, avasallando otros modos posibles de la razón.

En el texto sobre el cierre del universo político, Marcuse plantea la discusión en torno a las coordenadas sociales y geopolíticas de la posibilidad de emergencia de una subjetividad política emancipatoria. La lógica productivista es la clave de su crítica. El individuo administrado se encuentra integrado, asimilado y automatizado en un trabajo alienado cuya ideología totalitaria se funda en que el propio deseo subjetivo sostiene al sistema de dominación. Estas cuestiones anticipan y nutren las discusiones que en las décadas subsiguientes se inscriben bajo el lenguaje de los estudios sobre la biopolítica, las políticas de la experiencia y la subjetividad en la trama de las sociedades contemporáneas (Fischetti y Cuervo Sola 2011, Cuervo Sola 2012).

En el aspecto geopolítico, Marcuse presenta en espejo a la sociedad capitalista del Estado de bienestar norteamericano y a la sociedad del socialismo real propia del marxismo soviético. En ambas, las posibilidades emancipatorias serían reabsorbidas desde lógicas productivistas, asentadas en la racionalidad tecnológica.

Marcuse lee la sociedad norteamericana en la que está inmerso como una sociedad cerrada, que ha logrado integrar todas las dimensiones de la existencia, tanto pública como privada. Esta integración se produce también en los trabajadores de la fábrica que, a partir del mismo proceso material de producción, se asimilan al sistema al nivel de sus necesidades e intereses. Marcuse denuncia que el pluralismo que aparentemente ofrecen los mercados es ideológico y engañoso, ya que promueve una inevitable asimilación al sistema. La integración en todos los campos es posible por el avance de la productividad, 
regida por la racionalidad tecnológica y la creciente conquista de la naturaleza y la propia vida humana que suscita.

El cierre del universo político se da para Marcuse por el fetichismo de la tecnología (Fischetti 2014) y es el desarrollo tecnológico también su clave de lectura geopolítica. El énfasis está puesto en el cierre del universo político, en la clausura de esa interioridad trascendente que puede hacer advenir un nuevo mundo al aquende. Ahora bien, ¿dónde aparecen, según Marcuse, puntos de dislocación de esta confortable dinámica subjetiva que caracteriza a las sociedades modernas?

En este escrito, Marcuse señala dos posibles clivajes que podrían cuestionar la homogenización de la superficie social que genera la racionalidad tecnológica: una, de corte más bien sociológico, se refiere al lugar que ocupan los desheredados de las sociedades industrializadas; otra, de tipo más bien geopolítico, se refiere a los países o territorios de zonas subdesarrolladas y que en esa época se perfilaban, por ejemplo, en la liga de los países no alineados, como el posible emergente de una tercera fuerza en lucha contra las dos formas de organización de la sociedades industrializadas.

Si bien Marcuse reconoce el rol histórico que podrían cumplir los desheredados, señala también en este capítulo de El hombre unidimensional las contradicciones políticas que enfrenta este sector social como opción política efectiva. Nos dice entonces:

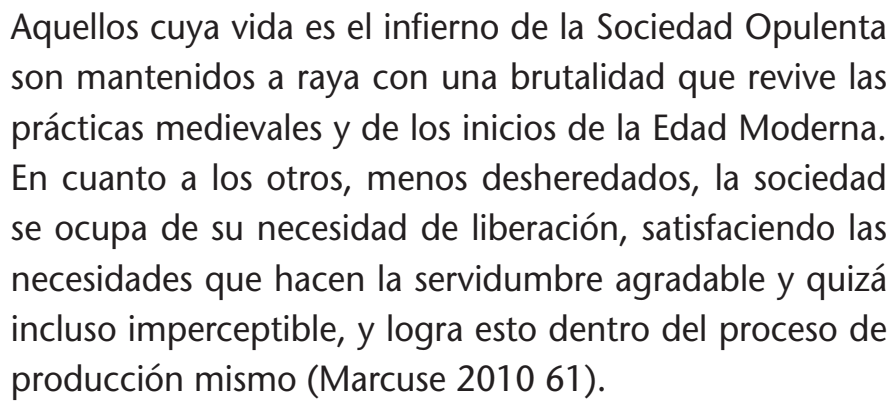

La brutalidad con la que se mantiene a raya a los desheredados es justamente el índice de las potencialidades disruptivas que este sector social alberga respecto del régimen imperante. Enfoquémonos ahora 
en el segundo clivaje: el geopolítico, que es el punto que más nos interesa en este trabajo. Refiriéndose a esta cuestión, Marcuse comenta:

la opinión de que el nuevo desarrollo de los países atrasados pueda no solo alterar las perspectivas de los países industrialmente avanzados, sino incluso constituir una "tercera fuerza" capaz de crecer hasta convertirse en un poder relativamente independiente. Dentro de los términos de la discusión anterior, ¿hay alguna evidencia de que las antiguas áreas coloniales o semi-coloniales puedan adoptar una forma de industrialización diferente de la del capitalismo y el comunismo de hoy?, ¿hay algo en la tradición y la cultura autóctona de estas áreas que pueda indicar tal alternativa? Limitaré mis comentarios a los países atrasados que están ya en proceso de industrialización, esto es, aquellos en que la industrialización coexiste con una resistente cultura pre y anti-industrial (India, Egipto). (Id. 79).

Básicamente, la tesis de Marcuse sobre las posibilidades disruptivas del emergente tercermundista (analizado solo en los casos de la India y Egipto en su escrito) es la siguiente: las regiones atrasadas, que antiguamente fueron colonias o semicolonias, no tienen grandes posibilidades de generar una vía de industrialización y desarrollo tecnológico alternativa a la que proponen el capitalismo y comunismo (que, como vimos, responden a una misma racionalidad), por el hecho de que precisan para ello de una instancia de "acumulación primitiva" de capital. Y ello solo puede generarse — según Marcuse- por medio de excedentes provenientes del exterior (ya sea que se trate de inversiones realizadas desde el bloque capitalista o comunista) o mediante la instauración de una dictadura que promueva un proceso de sobreexplotación de su propia población y recursos, a fin de gestar esa acumulación originaria necesaria para disparar un ciclo económico de desarrollo tecnológico y aumento de la productividad.

La única posibilidad de ruptura en este segundo clivaje podría tener lugar, según Marcuse, si el proceso político de desarrollo económico de estas sociedades se realiza a través de la incorporación de tecnologías 
para aumentar la productividad del trabajo, de manera subordinada a los propios rasgos culturales y formas productivas tradicionales. Sin embargo, incluso en el remoto caso de que esto fuera posible — afirma Marcuse-, esto tendría que darse en el marco de un retroceso y/o abandono por parte de los dos grandes bloques de poder mundial de sus políticas de subordinación imperialista de las zonas subdesarrolladas. Una virtualidad de espinosa concreción.

Por ello su insistencia en señalar que asistimos al cierre del universo político. La dinámica social que se desarrolla a partir de la automatización y el confort consumista, escribe el obituario de cualquier posibilidad de novedad histórica. Los clivajes que podrían operar una apertura del campo de las posibilidades históricas evanecen frente a la potencia de la racionalidad tecnológica. Al respecto, Marcuse nos dice: "En suma, es muy probable que las áreas retrasadas sucumban ya sea a una de las diversas formas de neocolonialismo o a un sistema más o menos terrorista de acumulación primitiva" (Marcuse 2010 80).

Ahora bien, llegados a este punto nos preguntamos: ¿se produce en nuestros países latinoamericanos, en esos años, un cierre del universo político tal como el que apunta Marcuse? ¿Efectivamente los procesos de industrialización incipiente de las economías de esta parte del mundo anuncian la captura definitiva de las potencialidades de trascendencia del sistema que habitan en la inmanencia proletaria bajo la racionalidad tecnológica productivista? ¿Acaso la única posibilidad de una alternativa histórica para nuestra América se juega en una inverosímil abdicación del poder de los imperialismos para estas latitudes?

La hipótesis que desarrollamos en este escrito propone dar una respuesta negativa a estas preguntas; en los márgenes espaciales, en los intersticios temporales de esa formidable expansión planetaria de la racionalidad tecnológica de posguerra, que tan profundamente describe Marcuse, se desarrollaron reflexiones teóricas alumbradas por proyectos políticos que señalaban efectivamente otro horizonte histórico posible para Latinoamérica, otras posibilidades para metabolizar las densidades constrictivas del desarrollo económico y el progreso técnico. 


\section{Irrupciones del pensamiento político latinoamericano}

Algunas décadas antes de los años 60 ya se comenzaba a problematizar en los debates latinoamericanos los desafíos económico-políticos que planteaba la cuestión del subdesarrollo-desarrollo.

Ya tempranamente, en los estudios realizados por Raúl Prebisch en los años 40 , que se publicarían algún tiempo después como documentos de trabajo en la ONU (Prebisch 1949 1950), se formulan una serie de críticas a los enfoques lineales del desarrollo económico y se esboza ya un idea fuerza central para el pensamiento económico político latinoamericano: el concepto de sistema "centro-periferia", a partir del cual se pone en evidencia la necesidad de abandonar el estudio de las economías de esta porción del mundo como realidades aisladas y emprender su análisis como parte constitutiva de un sistema articulado de relaciones económicas, cuya dinámica de intercambio tendería a perjudicar cíclicamente la situación de las países periféricos en favor de los centrales. A partir de un trabajo de reconstrucción y estudio de series estadísticas, esfuerzo científico metodológico ciertamente innovador para la época, Prebisch sostiene que la persistencia de las asimetrías en el sistema "centro-periferia" se verían promovidas por las disparidades en las elasticidades de las demandas de importaciones entre centros y periferias (es decir, cuando el ciclo económico ingresa en la fase recesiva, en las periferias la propensión a la importación se mantendría alta, generando una crisis en el sector externo) y por el deterioro tendencial de las condiciones de intercambio de las exportaciones de productos primarios (que hace que los precios relativos entre manufacturas y productos primarios favorezcan tendencialmente a los países centrales en detrimento de los periféricos). Aquí encontramos las primeras tesis que sirven de cimiento para los debates posteriores del pensamiento económico político latinoamericano.

A partir de los años 50, con la crisis de los nacionalismos populares y de los procesos de industrialización por sustitución de importaciones que tuvieron su apogeo entre los años 30 y 40, numerosos autores, entre los que podemos mencionar a Helio Jaguaribe o Rogelio Fri- 
gerio, comienzan a señalar la existencia de limitantes estructurales que, por la propia dinámica económica capitalista, aún en escenarios de crecimiento económico y expansión, terminan profundizando la situación de subdesarrollo. Por ejemplo, Jaguaribe, en su obra Burguesía y Proletariado en el Nacionalismo Brasileño (1961) pone de relieve los aspectos políticos del subdesarrollo: la existencia de relaciones de poder al interior de las sociedades subdesarrolladas, y de éstas con los países centrales, que bloquean las posibilidades de estas formaciones sociales para profundizar el proceso de acumulación de capital y de desarrollo de las fuerzas productivas. En efecto, este autor sostiene que la sociedad brasileña, y de manera general las economías subdesarrolladas, se caracterizan por sufrir condiciones de subcapitalización, producto de la falta de disponibilidad de una parte relevante de la renta para destinar a la inversión. Esto se explica —-según el clásico brasileño_- por la alta propensión a aumentar el consumo que muestran las masas ante crecimientos en el producto nacional debido a que la capacidad de consumo de las mismas, ya en el punto de partida del proceso económico, es extremadamente baja. Jaguaribe sostiene que esta condición de pauperización en la que se encuentran las masas responde al alto nivel de parasitismo y privilegios existentes en la economía brasileña. Esto conduce, según Jaguaribe, a que se produzcan, en los momentos de expansión económica, pujas distributivas que concluyen con aumentos salariales superiores al ritmo de evolución de la productividad del trabajo y, al mismo tiempo, que se expandan las clases medias que no se insertan en ningún proceso productivo y promueven lo que denomina el "parasitismo del Estado" o el "Estado cartorial"4. Estas tendencias

\footnotetext{
${ }^{4}$ El término "Estado cartorial" es acuñado por Helio Jaguaribe para enfatizar las propiedades parasitarias que, según su visión, caracterizan a la formación estatal brasileña. El término se deriva del nombre de una institución judicial del periodo colonial, os cartoriós, que eran los encargados de preservar las documentaciones de los procesos, así como también de certificar su autenticidad. La declinación cartorial que Jaguaribe reconoce en el Estado brasileño intenta señalar el crecimiento excesivo del sistema burocrático, no en función de los requerimientos de una más efectiva prestación de servicios públicos, sino en función de la generación de empleos relativamente improductivos y bien remunerados en favor de ciertos sectores sociales.
} 
que muestran las economías subdesarrolladas conducen, según Jaguaribe, a la escasez de excedente para destinar a la inversión. Dicha conclusión, a la que arriba, constituye el diagnóstico de base que hacen las corrientes del desarrollismo clásico latinoamericano sobre los problemas económicos de la región. Para el caso de la Argentina, esta posición se expresó, por ejemplo, en el pensamiento de Rogelio Frigerio (1959 1963).

Frente al problema de subcapitalización de las economías subdesarrolladas, Jaguaribe señala dos grandes estrategias que pueden asumirse para intentar superarlo: la primera de ellas, que identifica bajo el nombre de "estrategia cosmopolita y neocolonialista", es la que apuesta a la inversión extranjera como vector dinamizador del desarrollo, manteniendo así las condiciones de heteronomía y exogenia heredadas del periodo colonial; la segunda, que denomina "estrategia del nacionalismo integrador desarrollista", es la que, según su opinión, tendría que asumir la sociedad brasileña para conducir su proceso económico, político y social hacia un horizonte de mayor autonomía nacional. Según Jaguaribe, poca relevancia práctica tiene para países con el nivel de desarrollo-subdesarrollo como Brasil o Argentina la discusión sobre si es el modelo capitalista o el modelo socialista el que debe orientar el proceso de desarrollo. Para Jaguaribe, uno y otro modelo mostraban tendencias confluyentes en esos años respecto de los niveles de bienestar alcanzados por los trabajadores y de los modos de gestión del proceso productivo.

Jaguaribe apuesta en su escrito por una convocatoria a los sectores más dinámicos de la burguesía brasileña a asumir el papel de conducción del proceso histórico, articulando en su proyecto a las clases medias y al proletariado, para generar una profunda transformación social que reduzca los privilegios y el parasitismo de las clases superiores, expanda la eficiencia y la austeridad de la función empresarial, y promueva una democracia de masas que aumente los niveles de igualdad política y social en el Brasil. En Desarrollo Económico y Desarrollo Político insiste con estas tesis, aunque propone realizar mayores distinciones al interior de las dos grandes estrategias que podría asumir Brasil para desarrollarse (Jaguaribe 1962201 y ss.). 
Por un lado, distingue entre el "cosmopolitismo liberal", que asume la política del librecambio como bandera y expresa a los intereses coloniales del Brasil (burguesía urbana mercantil, burguesía rural señorial y burguesía rural capitalista), y el "cosmopolitismo desarrollista", que cifra sus esperanzas de desarrollo en la abstención del Estado para intervenir en la economía y en el arribo de inversiones extranjeras para controlar los sectores claves de la economía. Por otro lado, en el campo del nacionalismo, distingue entre el "nacionalismo socializante estatista", de inspiración marxista y social cristiana, que plantea el manejo estatal directo de la actividad económica con el fin de garantizar, no solo la instauración del socialismo, sino, centralmente, el desarrollo; el "nacionalismo burocratizante", que se distingue del anterior por buscar permanecer dentro de las fronteras del capitalismo, promoviendo la coexistencia entre empresas públicas y privadas, con una mayor redistribución de la renta y aceleración de la tasa de capitalización (esta estrategia representaría el proyecto del proletariado cartorial); y el "nacionalismo desarrollista", opción por la que apuesta Jaguaribe, que se propone una planificación global de la economía para lograr la máxima y mejor utilización de factores de producción, pero cuyo motor debe ser la empresa privada, y que representaría el proyecto de la burguesía urbana industrial y de la clase media urbana y rural tecnológica.

Quizás en estos escritos de Jaguaribe se pueda ver con mucha claridad el modo en que muchos intelectuales y políticos latinoamericanos cifraron sus esperanzas para alcanzar el desarrollo económico durante las primeras experiencias de los nacionalismos populares y de los gobiernos desarrollistas subsiguientes: la constitución de una verdadera burguesía nacional que condujera el proceso histórico de acumulación y desarrollo técnico.

Sin embargo, estas esperanzas se mostraron crecientemente ilusorias a medida que avanzaba la década del 60: en efecto, frente a la falta de recursos para profundizar el ritmo de inversión y dar un salto cualitativo de la fase sustitutiva de importaciones para comenzar a producir localmente los bienes de capital, los sectores industriales realizan un significativo giro político que los lleva a retirar su apoyo a los regímenes 
nacional populares, a abandonar el frente político de clases previo y a reconstituir sus alianzas de clases con los sectores trasnacionales de la economía. Es decir, los sectores industriales terminarían enrolándose mayoritariamente en lo que Jaguaribe denominó la estrategia del cosmopolitismo desarrollista.

Este factum histórico abrió un proceso de fuertes luchas políticas y profundos debates teóricos en América Latina. A la luz del mismo, el incipiente desarrollismo latinoamericano adquirió densidad teórica y abrió paso a la constelación de producciones que se agruparían bajo la denominación de "Teoría de la Dependencia" o, para usar un término más preciso, del "dependentismo", ya que se trató de un conjunto de discusiones teórico-políticas que bullía en los más diversos ámbitos de la militancia política y excedió largamente el circuito de intelectuales vinculados a la CEPAL.

Un estudio epicéntrico de estos debates, y que muestra la incorporación de las consecuencias de este factum histórico a la reflexión teórica, fue Dependencia y desarrollo en América Latina, de Cardoso y Faletto $(1969)^{5}$. En este ensayo, los autores plantean que, en América Latina, "se llegó a suponer que para lograr el desarrollo en los países de la periferia es necesario repetir la fase evolutiva de las economías de los países centrales" (31). Los autores insisten en las inconsistencias que señalara Prebisch en aquellas políticas diseñadas desde un enfoque evolucionista y lineal de los procesos de desarrollo, que pierden de vista la trama de relaciones de poder que estructuran la dinámica económica. Confirman la necesidad de tener un abordaje del asunto que haga hincapié en el sistema de relaciones centro-periferia, que son las que profundizan la condición de subdesarrollo latinoamericano, incluso en fases de expansión económica e industrialización. Por ello, afirman que, para explicar la persistencia de la situación de subdesarrollo en que se encuentran los países latinoamericanos, no es suficiente el concepto de "dualismo estructural" que sostiene el desarrollismo

5 Ensayo escrito por los autores entre 1966 y 1967, en Santiago de Chile, mientras trabajaban en el Instituto Latinoamericano y del Caribe de Planificación Económica y Social (ILPES) de la CEPAL. 
clásico. La reproducción del subdesarrollo no se explicaría exclusivamente por la hibridación entre un sector productivo tradicional que se fue articulando, con la expansión del capitalismo, con un sector productivo dinámico ligado al mercado mundial; hibridación que produciría rigideces estructurales que bloquean el camino al desarrollo. Los autores reorientan el foco para percibir la doble conexión que se establece entre las características internas de la economía y su articulación con la dinámica externa. De este modo, como elemento determinante de la reproducción del subdesarrollo aparece el hecho de que, desde la propia fase colonial, las economías latinoamericanas estarían articuladas al sistema capitalista desde una posición periférica. Es decir, serían economías plenamente capitalistas, pero ya desde el origen, bajo la forma de un capitalismo dependiente.

Por ello, dicen los autores, no se trata de preguntarse en qué fase del capitalismo están nuestras economías: son parte constitutiva del sistema capitalista internacional desde sus inicios y son, por lo tanto, contemporáneas a él; están en la misma fase en la que se encuentra el capitalismo en ese momento histórico en el plano internacional. De lo que se trata es de preguntarse entonces qué significó, en términos de "estructuras de la economía" y "estructura social", la relación de dependencia para los países latinoamericanos en cada una de esas fases de desarrollo del capitalismo mundial y en relación a los diversos centros económicos que tuvieron esas fases.

Luego del periodo colonial, en el cual las economías latinoamericanas estaban centralmente atadas a la dinámica económica de las metrópolis peninsulares (España y Portugal), el predominio internacional se desplaza a Inglaterra. Durante el siglo XIX, entonces, nos dicen los autores, mientras se gestaba la independencia y se consolidaban las formaciones estatales nacionales a lo largo del subcontinente

se produce el paso a la dependencia de Inglaterra [que] tiene como sostén social al grupo de productores nacionales, que por el crecimiento de su base económica — crecimiento ya dado en la situación colonial— estaban en condiciones de suscitar un nuevo acuerdo entre las distintas fuerzas sociales gracias al cual estaban llamados 
a tener, si no el dominio absoluto, por lo menos una situación privilegiada (35).

En esta fase, entonces, los sectores exportadores de materias primas se consolidan como aquellos económicamente más dinámicos y asumen la función directriz en las formaciones sociales latinoamericanas.

En este punto, Cardoso y Faletto introducen una distinción relevante en relación a si el sector exportador se encuentra en manos directas de empresas extranjeras (economía de enclave) o bajo control de capitales nacionales que se articulan de manera subordinada al mercado mundial. Este segundo caso (que caracteriza a economías como las de Argentina, Brasil y México, entre otras) será condición de posibilidad para que en la siguiente fase de desarrollo capitalista, en la cual la hegemonía mundial se traslada hacia los Estados Unidos, algunas economías latinoamericanas logren consolidar un mercado interno relativamente amplio y un incipiente proceso de industrialización sustitutiva de importaciones, coadyuvadas por las condiciones de proteccionismo indirecto que generan las guerras mundiales.

Sobre estos cambios económicos y sociales tendrán lugar las experiencias nacional populares de mediados del siglo XX. Sin embargo, sostienen los autores, estos procesos políticos no lograron consolidar una situación de autonomía económica nacional que les permitiera a los países latinoamericanos desplazarse de su condición de dependencia. El volumen de inversiones de la economía local no alcanzó para sostener la dinámica de industrialización y el deterioro de los términos de intercambio produjo el estrangulamiento externo de las economías: se trata de la crisis de las experiencias nacional populares. Dos posibles caminos se abren, según los autores, para sortear estos obstáculos: abrir la economía a la incorporación de capitales extranjeros o un cambio político radical hacia el socialismo (138). Sin embargo, Cardoso y Faletto no ahondan en esta segunda opción en su ensayo y concentran su atención en analizar la primera de ellas, que es la que estarían siguiendo las economías latinoamericanas en los años 60 bajo los gobiernos y las dictaduras desarrollistas. 
En efecto, los autores plantean que, durante estos años, se produce un cambio relevante en la dinámica del subdesarrollo, y se pasa de economías cuyo crecimiento se encuentra fuertemente condicionado por el sector agroexportador (fase del predominio de Inglaterra) a economías cuyo motor se encuentra en el arribo de capitales extranjeros que invierten en sectores industriales, con el fin de capturar parte de los mercados internos latinoamericanos, que se han fortalecido sensiblemente con las experiencias nacional-populares y los procesos de industrialización sustitutiva. Esta modificación de las condiciones externas e internas de las economías latinoamericanas se produce, no casualmente, una vez que se alcanzan los equilibrios geopolíticos de posguerra y el predominio estadounidense sobre la región se hace presente nuevamente con toda su potencia.

El subdesarrollo latinoamericano de este periodo, entonces, se caracteriza por la apertura de los mercados internos al control externo: eso que, como vimos oportunamente con Jaguaribe, se denominó la "estrategia del cosmopolitismo desarrollista".

A pesar de que el arribo de inversiones extrajeras en sectores productivos altamente tecnificados, como el automotriz, podrían llevarnos a suponer que, en el periodo, existirían condiciones efectivas de superación del subdesarrollo, Cardoso y Faletto insisten en señalar que esto no implica la superación de la dependencia. Persiste una asimetría de poder entre centro y periferia, que induce el proceso económico en beneficio del primero, aun cuando se generan procesos de industrialización creciente e incorporación tecnológica en los países latinoamericanos.

¿Qué salida proponen frente a esta compleja trama de intereses, que bloquea las posibilidades de nuestra América para superar su condición dependiente? Más que un modelo o caracterización de los horizontes posibles — como vimos p.e. con Jaguaribe-, Cardoso y Faletto se limitan a afirmar la centralidad de la política en el asunto. La dependencia es un problema político, que tiene su expresión en la "estructura económica" y en la "estructura social", pero cuyo centro organizador radica en el poder político. 
Claramente, este estudio referido es simplemente una muestra de la multiplicidad de producciones teóricas y discusiones que abrieron los intelectuales de la Teoría de la Dependencia en esa época. Este breve itinerario de la reflexión latinoamericana en torno a los problemas del desarrollo, en el que sin lugar a dudas podría agregarse otras obras y autores, como Günder Frank, Theotonio Dos Santos, Aldo Ferrer, Ruy Mauro Marini, entre otros, muestra la creciente complejidad que el tratamiento de esta cuestión asumía en el campo científico latinoamericano.

Sin embargo, tal como señalamos, estos debates no se circunscribieron al ámbito académico, sino que fueron moneda corriente en las discusiones de los dirigentes y militantes políticos de los diversos movimientos que, en esa época, luchaban por alcanzar lo que José Martí llamó nuestra "segunda independencia".

Por ejemplo, en un registro estilístico propio del ensayo político, divergente de la argumentación científica que caracteriza los trabajos antes mencionados, John William Cooke ${ }^{6}$ publicaba, en 1966, en una escasa tirada de ejemplares que fueron distribuidos entre los militantes sindicales de base, su escrito Peronismo y Revolución. El peronismo y el golpe de Estado: informe a las bases (Cooke 1973). En este trabajo, que con los años se transformaría en un texto clásico de la resistencia peronista, Cooke condensa con mucha claridad los desafíos que enfrentan en ese momento los movimientos nacional populares que emergieron en los años 40 y 50. En efecto, a partir de un análisis que se detiene específicamente en la situación argentina ${ }^{7}$, el autor plantea que los

6 John William Cooke, político argentino que fue coordinador político de las resistencias peronistas luego del Golpe de Estado de 1955 que desplazó de la Presidencia a Juan Domingo Perón. Fue un dirigente epicéntrico del peronismo de los años 50 y 60 , cuya labor consistió en hilvanar paulatinamente, para brindar organicidad y unidad política, a la miríada dispersa de acciones de resistencia a la dictadura que, espontáneamente, las bases sindicales comenzaron a realizar con posterioridad al derrocamiento de Perón.

7 Se trata de un texto escrito con el fin de esclarecer las principales aristas que organizan el cuadro político de la República Argentina luego del Golpe de Estado de Onganía, de 1966, y advertir a las militancias sindicales sobre los riesgos de ceder a la convocatoria desarrollista que ofrecía la dictadura, en contubernio con parte de la dirigencia sindical. 
esfuerzos del proceso político, abierto con la irrupción de las masas en 1945, se orientaron a acrecentar los niveles de autonomía nacional a través de la intervención del Estado en la economía para promover y acelerar la industrialización, mejorar la distribución de la renta y consolidar la organización política de las masas. Si bien, para Cooke, el motor de este proceso político estuvo en la clase trabajadora, uno de los principales beneficiarios del mismo fue la burguesía industrial local, que consiguió incentivos para desarrollarse a través del crédito público y la expansión del consumo. Sin embargo, señala Cooke, cuando las circunstancias económicas se volvieron relativamente adversas, a partir del año 53, la burguesía industrial cambió de estrategia política, y se articuló con los sectores opositores al gobierno, que eran liderados por las oligarquías pampeanas y los agroexportadores y lograron derrocar al gobierno popular. La burguesía industrial, entonces, se articuló con el sector agropecuario y con los capitales internacionales, para profundizar el proceso de acumulación de capital bajo los lineamientos del proyecto desarrollista que proponía la estrategia de EE.UU. para el subcontinente: Ia Alianza para el Progreso. Las dictaduras sesentistas en América del Sur (como la de Onganía en Argentina, 1966-1973) consistieron en el intento de controlar la resistencia que ofrecían los frentes políticos populares a este giro del proceso de industrialización en un sentido proimperialista y extranjerizante. Frente a estas circunstancias, Cooke advertía en su escrito que el único camino para alcanzar una efectiva soberanía nacional, y superar la situación de dependencia a la que estaba sometido el país, consistía en radicalizar la lucha política. Ante la defección sistemática de la burguesía nacional para asumir el papel que le exigía por ejemplo en sus escritos Jaguaribe, producto justamente de la condición dependiente del país, eran los trabajadores los que debían asumir la posta. Cooke plantea claramente que el camino para que no aborte el proceso de industrialización en curso y quede atrapado en la dependencia y el subdesarrollo es el de avanzar hacia el socialismo (un socialismo que claramente no es de inspiración soviética, sino tercermundista).

Estas conclusiones políticas fueron desarrolladas en el marco de los debates teóricos del dependentismo, entre otros, por Franz Hinkelammert, quien también reflexionaba sobre los problemas de la 
dependencia y el subdesarrollo a la luz de las luchas políticas que en esos años fulguraban a lo largo y ancho de las geografías de nuestra América, y especialmente en relación a la singularísima experiencia política de la Unidad Popular en Chille, con Salvador Allende.

\section{El pensamiento crítico desde un locus latinoamericano: Hinkelammert y la apuesta por la política}

Retomamos a partir de aquí la referida noción roigeana de "universo discursivo" y consideramos al texto marcuseano del 64 como un "pretexto" para explorar en las posibilidades, contemporáneas de aquel, de apertura de la teoría y la praxis política desde un sujeto político latinoamericano protagónico, no alienado.

Nos introducimos en la búsqueda de alternativas teórico-políticas y afirmamos que hay ciertas características de la dinámica política, económica y social de los países del entonces llamado "Tercer Mundo", que son desatendidas por Marcuse, situación que lo lleva a menospreciar en su análisis las posibilidades políticas que habitan en estos territorios. Estas peculiaridades de las economías dependientes explicarían cierta insuficiencia en la tesis del autor frankfurtiano, acerca de la depotenciación política que conllevaría la incorporación creciente de trabajadores a cadenas de agregación de valor altamente tecnificadas, de alta productividad y con salarios que les permiten alcanzar un elevado nivel de consumo.

Tal como manifestamos en párrafos precedentes, encontramos que los conceptos que vierte Marcuse en su reflexión sobre el cierre del universo político (clausura que, según este autor, estaría acaeciendo en las sociedades industrializadas de posguerra) no resultan suficientemente productivos para abordar críticamente la realidad política y económica latinoamericana de esos años.

La obra de Franz Hinkelammert tiene características muy particulares, que la hacen especialmente adecuada para poner al autor en diálogo con Herbert Marcuse. Su pensamiento, que se nutre claramente en raíces de la primera Escuela de Frankfurt, se encuentra al mismo tiempo 
radicalmente inmerso en la reflexión y problemáticas propiamente latinoamericanas (Fernández Nadal 2012). Hinkelammert, economista y teólogo nacido en Alemania, y latinoamericano por opción política y de vida, arribó a Chile en 1963, luego de terminar sus estudios en la Universidad Libre de Berlín, y se incorporó rápidamente a los debates teórico-políticos que tenían lugar en América Latina en esa época, uno de cuyos epicentros se encontraba en el ILPES (Instituto Latinoamericano y del Caribe de Planificación Económica y Social) de la CEPAL (Comisión Económica para América Latina y el Caribe), radicado en Santiago de Chile.

Su escrito El subdesarrollo latinoamericano. Un caso de desarrollo capitalista comienza cuestionándose sobre el modo como se coordina la división internacional del trabajo: "La tesis principal de este trabajo —nos dice - es que el mercado capitalista mundial como sistema de coordinación internacional del trabajo impide a un gran número de países lograr un equilibrio interno del trabajo. A estos países los llamamos entonces subdesarrollados" (Hinkelammert 1970 14). Los conceptos que propone en esta obra ya perfilan con una claridad meridiana el contrapunto que queremos marcar respecto de cómo, en ese momento, en América latina estaríamos en presencia de una apertura del universo político, que sería cerrado recién algunos años después, con el advenimiento de las dictaduras genocidas neoliberales. Hinkelammert sostiene que el alto desarrollo técnico de los países centrales genera desequilibrios en las sociedades latinoamericanas, ya que destruye los espacios tradicionales de producción. Sobre este punto, el autor afirma que existen dos tipos de dualidades: la de la sociedad tradicional y la sociedad capitalista desarrollada; y la de la sociedad subdesarrollada y la sociedad en vías de desarrollo.

Con respecto a la primera dualidad, la sociedad tradicional es definida por Hinkelammert como carente de progreso técnico consciente. En este sentido, afirma, "se puede decir que la actitud tradicional frente a la economía concibe la técnica como una parte de la naturaleza que es aprovechada pero no desarrollada. Falta totalmente la eficiencia como criterio orientador de la conducta" (Id. 24). Sin 
embargo, la ética tradicional de la buena voluntad que se somete a las estructuras dadas se transforma, ante el avance capitalista en estas sociedades, en la ética del trabajo, base ideológica de toda sociedad moderna, regida por la idea de "progreso". Por el contrario, en las sociedades desarrolladas, la clase capitalista puja por una economía que "metódicamente y sin cesar cambia sus técnicas y sus medios de producción, y que genera, por lo tanto, un proceso de crecimiento económico sin un límite preestablecido" (Id. 26). En relación a aquellos cambios estructurales, en dialéctica con la ideología, Hinkelammert explica cómo el Estado, en tanto poder de vigilancia para la conservación del statu quo de la clase capitalista, se transforma en Estado de bienestar, que impulsa la iniciativa basada en la propiedad privada y contiene la rebelión de las clases desfavorecidas. La técnica asume el rol predominante y se transforma en el medio para la conquista del mundo y el progreso. La ética del trabajo es finalmente ética del progreso.

Ante la segunda dualidad —la que tiene lugar entre sociedad subdesarrollada y sociedad en vías de desarrollo-, Hinkelammert alega que es preciso distinguir entre, por un lado, el subdesarrollo, propio de una formación social contradictoria y cualitativamente diferente a la desarrollada (es decir, una sociedad no atrasada, sino desajustada por la propia dinámica desarrollo-subdesarrollo), y, por otro lado, un tipo de sociedad:

que podemos llamar sociedad en vías de desarrollo, y que se distingue de la anterior no por el nivel económico, sino por el hecho de haber encontrado una manera eficaz de revertir el proceso de subdesarrollo a partir de una especie de catalizador que permite orientar la sociedad en un camino de desarrollo factible (Id. 36).

La progresiva inserción comercial de las economías latinoamericanas en el mercado mundial a lo largo del siglo XIX desató un proceso de explosión demográfica y destrucción de la industria tradicional (por la orientación de la economía al intercambio basado en la producción de materias primas). Es la incapacidad de nuestros países, de anticipar estos efectos secundarios del encuentro cultural con los países 
desarrollados, lo que produce nuestro subdesarrollo, afirma. Lo de "encuentro" es un eufemismo, explica, y lo sabemos: estamos ante un imperialismo de extracción, que se extiende hasta la Segunda Guerra Mundial, que redunda para los países latinoamericanos en una dependencia de tipo indirecto y que luego deviene en estructural. El imperialismo es estructural; aunque en los países desarrollados, inmersos en la ideológica liberal capitalista, que habla de libertad y considera que el colonialismo es un problema resuelto, se lo denomine simplemente como "estabilidad del mercado capitalista mundial". Al respecto, Hinkelammert afirma que:

El paso del imperialismo de extracción a la nueva etapa del imperialismo estructural de estabilización, no significó más que el reemplazo de los lazos directos entre los diferentes poderes imperialistas y sus respectivas colonias por una relación centro-periférica, en la cual los países capitalistas tienen bajo su poder todo el mundo subdesarrollado como si fuera una sola gran colonia común (Id. 59).

Para Hinkelammert, sin embargo, los efectos de la explotación no pueden ser considerados las causas del subdesarrollo, así como la inversión extranjera no puede ser motor del desarrollo latinoamericano:

Estas inversiones no pueden considerarse como motores del desarrollo, pues dan origen a sucursales de empresas centrales, que manteniendo toda la actividad destinada a impulsar el progreso tecnológico en el centro mundial, trasplantan al país subdesarrollado solamente ciertos tipos de producción acordes con la tecnología creada en el extranjero (Id. 60).

Denuncia entonces un círculo vicioso: "la explotación imperialista presupone el subdesarrollo y éste provoca la dependencia" (60-61), porque es la estructura misma del capitalismo la que determina el surgimiento del subdesarrollo. Nos dice entonces:

La estructura capitalista solo permite un desarrollo paulatino, gradual e interdependiente de técnicas, estructuras sociales, actitudes de trabajo y convicciones ideológicas. 
Una vez perdido el momento histórico en que existía una diferencia pequeña entre la estructura desarrollada y la estructura tradicional, el progreso técnico de los países desarrollados dificulta el tránsito de los países subdesarrollados hacia el desarrollo conservando la estructura capitalista. La estabilización del sistema capitalista mundial acarreó la reproducción continua del subdesarrollo (Id. 75).

Es decir que, en el marco del capitalismo, no resulta factible la superación del subdesarrollo y es preciso una radicalización de la lucha política emancipatoria y de su concomitante crítica teórica.

Frente a este análisis, Hinkelammert propone la noción de "factibilidad histórica", en tanto probabilidad que depende de elementos voluntarios de los seres humanos determinados, pero también hacedores de la historia. Es decir que, en última instancia, el cambio histórico sucede por voluntad, elección y actuación política. Mientras tanto, afirma que la estructura capitalista frena el salto al desarrollo al asimilarlo al desarrollo de la técnica y de la conciencia ideológica.

Sobre esta base, intenta reflexionar acerca de las vicisitudes de los intentos de tránsito al desarrollo que han tenido lugar en los países periféricos desde mediados del siglo XX. Afirma que las dinámicas económicas y políticas que abrieron los populismos nacionalistas latinoamericanos generaron, a poco andar, una serie de contradicciones que pusieron de manifiesto la necesidad de generar cambios profundos en la correlación de fuerzas de las diversas clases y fracciones de clases de las sociedades subdesarrolladas (Id. 91 y ss.). Con las crisis del modelo de crecimiento e industrialización sustitutiva de los gobiernos nacional-populares, nos dice, surgen dos estrategias que, a pesar de sus diferencias, insisten en la vía capitalista para el desarrollo: las estrategias socialdemócratas, que buscan promover reformas desde el gobierno, para inclinar la balanza en favor de la fracción desarrollista de la clase dominante, y las estrategias populares, que intentan saldar el hiato del subdesarrollo con organización política en el nivel de las bases: "la organización del pueblo a nivel vecinal, sindical y cooperativo, haciendo hincapié en la dimensión social de dicha organización" (Id. 94). 
Sin embargo, sostiene el autor, una y otra estrategia fracasan en la consolidación de frentes pluriclasistas para emprender los desafíos políticos del desarrollo, ya que las clases dominantes, y especialmente la burguesía industrial, defecciona sistemáticamente de su rol directriz en ese proceso y promueve la colusión de sus intereses, por medio de su articulación societaria con empresas trasnacionales, con los intereses imperialistas.

Frente a este impasse de las vías populistas para el desarrollo, a mediados de los años 60 los procesos de acumulación política popular que se inician con los gobiernos populares de los años 40 y 50, y que se profundizan con las experiencias de densificación de los niveles de organización política de las bases, comienzan un proceso de radicalización que los lleva a plantear la necesidad de abrir una vía no capitalista para el desarrollo. Las dictaduras militares de tipo neofascista, antipopulares y desarrollistas de mediados de los 60 (como la brasileña de 1964 y la argentina de 1966) son una reacción a estas circunstancias. Surgen para garantizar la continuidad de la vía capitalista de desarrollo, con el doble objetivo de constreñir el proceso de creciente organización política popular y, paralelamente, forzar a las burguesías locales a asumir un rol más activo en el proceso de acumulación de capital en alianza con las empresas trasnacionales ${ }^{8}$.

En este punto, Hinkelammert introduce una distinción que es crucial para el argumento que venimos desarrollando. En efecto, este autor diferencia claramente entre estas dictaduras desarrollistas proimperialistas que irrumpen a mediados de los 60 en América Latina, de gobiernos como el de Nasser en Egipto que, según su perspectiva y a pesar de mostrar ciertas similitudes formales con las dictaduras latinoamericanas, nace de la lucha antiimperialista del pueblo egipcio

8 Para el caso argentino, por ejemplo, existen unos estudios muy detallados realizados en la época por Rogelio García Lupo (1968 1971), en los que se denuncia la colusión de intereses entre los funcionarios del gobierno de facto de Onganía, las burguesías locales y las empresas trasnacionales. En ellos se muestra la red de vínculos que se teje, muchos de ellos directamente familiares, entre funcionarios, empresarios y gerentes de las filiales locales de las empresas trasnacionales. 
y genera condiciones para la radicalización política popular y la vía no capitalista al desarrollo.

Hinkelammert sostiene, entonces, que el camino para saldar el impasse que se abre con la crisis de los populismos consiste en abrir una vía antiimperialista y no capitalista para el desarrollo. Este camino debe encaminarse a radicalizar el proceso de creciente politización popular, que ya está en curso en la región, hacia la instauración de un socialismo democrático, que evite el ruinoso autoritarismo del socialismo burocrático soviético (que se construye sobre la base de la burocracia estatal al mando de una elite autoelegida y que asume su dictadura como proyecto histórico). El socialismo democrático al que refiere Hinkelammert está claramente inspirado en la experiencia política del allendismo y su ideal histórico es alcanzar una sociedad sin clases en la cual no se pretenda una imposible desaparición del poder y la política en favor de "la simple administración de las cosas", sino que, por el contrario, organice el propio proceso económico sobre la base de la movilización política del pueblo.

Entendemos que, a partir de Hinkelammert, podemos identificar una dialéctica propia del proceso de organización política popular que comienza con las experiencias nacional-populares y cuya radicalización "abre el universo político" para plantear una opción política alternativa, la del socialismo democrático latinoamericano, que evita la vía muerta de la explotación imperial capitalista para alcanzar el desarrollo económico y, paralelamente, elude las formas políticas autoritarias que caracterizan el socialismo real. En este sentido, Hinkelammert afirma que: "Es preciso pues, construir el proyecto histórico de un socialismo latinoamericano a partir del control de los grupos dominantes de la sociedad [sean estos empresarios o burócratas estatales] por la base popular con el fin de que sean auténticos representantes de la soberanía popular" (Id. 119).

El corazón del asunto para Hinkelammert es la política: no se trata de lograr una inverosímil abolición absoluta del mercado (y sus agentes, los empresarios) en favor de una pura planificación centralizada, ni de abolir absolutamente el estado (y sus agentes, los burócratas) en favor de una pura competencia de mercado, sino de subsumir sendas 
instancias de articulación institucional de una formación social, bajo la dinámica política de la organización popular.

\section{Aperturas desde el Sur, a modo de conclusiones}

En la relectura de un texto ya clásico, se nos hizo patente la necesidad de hacer una permanente vigilancia epistemológica sobre nuestros modos de abordar la realidad. Hemos buscado, entonces, reflexionar históricamente desde una posición teórico-metodológica, que es política en su ampliación de las lecturas hegemónicas que se difunden desde el Norte. Hemos planteado una lectura sincrónica ${ }^{9}$, desde una historia de las ideas latinoamericanas, capaz de poner en diálogo crítico problemáticas generadas desde contextos geográficos y políticos diferentes en un mismo momento histórico. Nos hallamos en el Sur, en la periferia, y desde allí buscamos ampliar la mirada acerca de problemas que siguen teniendo vigencia en Latinoamérica. Los problemas del desarrollo y el progreso, la pobreza y la exclusión, se inscriben en nuestra historia de ciertos modos que debemos seguir revisando, desde posiciones que no repitan discursos hegemónicos, centrales, de declinación eurocéntrica.

Quizás, la aguda mirada crítica que singularizó el pensamiento de Herbert Marcuse no logró ponderar suficientemente, al menos en el capítulo referido al cierre del universo político en El hombre unidimensional, las potencialidades políticas que albergaban los movimientos de liberación nacional que en los 60 destellaban a lo largo y ancho de las geografías del Sur. Los sectores populares de nuestra América supieron encarnar, en aquellos años, proyectos radicales de liberación nacional y de transformación social que impugnaron los caminos tradicionales de desarrollo económico.

9 Para consultar un estudio que vincula a Marcuse y a Hinkelammert, sugerimos el trabajo de Carlos Asselborn (2012) acerca de una relación posible de estos autores a propósito de un análisis filosófico expresado en términos diacrónicos, es decir, buscando referencias de ciertas categorías presentadas desde y para el presente. 
Estos sectores populares se componían mayoritariamente por trabajadores industriales urbanos, relativamente bien remunerados, que desarrollaban su labor en actividades de capital intensivo, y también por trabajadores pauperizados, que trabajaban en espacios productivos tradicionales, que no habían incorporado los adelantos tecnológicos de las sociedades industrializadas (la heterogeneidad estructural propia del subdesarrollo), pero que se encontraban funcionalmente articulados a la dinámica de acumulación impuesta por el sector más dinámico de la economía periférica y, por su intermedio, al ciclo de acumulación de la economía que actuaba como centro imperial.

En uno y otro caso, tanto los trabajadores bien remunerados, que accedían a estándares de consumo y confort relativamente altos, como los pauperizados de la economía tradicional, encontraron que una parte relevante del excedente que con su trabajo generaban se fugaba al exterior por vía de la explotación imperialista. El frente popular antiimperialista fue la respuesta que encontraron para luchar contra esta exacción de recursos: primero a través de los proyectos nacional-populares, que incluían a la burguesía industrial y apuntaban a reorientar ese excedente recuperado de las manos imperialistas para promover el desarrollo local de las fuerzas productivas; luego, con el factum histórico de la defección burguesa ya ocurrido, a través de procesos de creciente organización y radicalización política popular que llevarían a formular los proyectos del socialismo democrático latinoamericano.

Esto último nos muestra que los procesos políticos que impulsaron la industrialización y el desarrollo económico de los países del Tercer Mundo no necesariamente estaban condenados a sucumbir — tal como sugiere Marcuse en el capítulo referido- bajo alguna forma de neocolonialismo (del bloque capitalista o soviético), o bajo una dictadura terrorista que garantizara el proceso interno de acumulación primitiva. Y esto es así por diversas razones. En primer lugar, el sistema terrorista de acumulación primitiva ya ocurría desde cinco siglos en estos lados oscuros del mundo; no constituía, ni constituye, por lo tanto, una novedad histórica, sino el estado normal de cosas en el que vivieron y viven nuestras poblaciones. En segundo lugar, y en consonancia con lo antedicho, neocolonialismo 
y acumulación primitiva terrorista se dan de manera mancomunada en América Latina, justamente en oposición y como borramiento, de los procesos (proyectos) políticos de desarrollo económico autónomo. En tercer lugar, entonces, resulta evidente que, hacia la década del 60 , al menos en América Latina, el universo político no estaba cerrado, sino que, por el contrario, se encontraba plenamente abierto por la disputa entre un proyecto de desarrollo económico, industrialización e incorporación tecnológica de raigambre popular, y un proyecto terroristaneocolonial que se realizaría, no con las dictaduras desarrollistas de los 60 , sino recién con las dictaduras genocidas setentistas. Serían estas últimas las encargadas de borrar la potencia transformadora que había alcanzado la creciente organización política popular, suprimir el tejido industrial en torno del cual esa organización popular se consolidaba y reinsertar estas formaciones sociales de un modo políticamente subordinado y económicamente reprimarizado en el nuevo-viejo sistema de división internacional del trabajo (p.e. Pinochet en Chille, 1973; Videla en Argentina, 1976).

Por otra parte, hay una cierta característica de las sociedades industrializadas que Marcuse no pondera con suficiente profundidad y que explican, en parte, las posibilidades que tienen las mismas de absorber funcionalmente al viejo proletariado como feliz consumidor: nos referimos al hecho de que el origen de parte del excedente económico sobre el cual articulan su Estado de Bienestar está gestado en la renta extraordinaria que estos países obtienen en el intercambio asimétrico con las economías subdesarrolladas. La situación de asimetría favorable en la que se encuentran respecto de las economías menos desarrolladas permite a las sociedades altamente industrializadas transferir los aspectos más críticos de las fases descendentes del ciclo económico, morigerando así las tensiones que estos momentos pueden generar en las economías desarrolladas y en sus propias estructuras sociales. Esto quiere decir que las posibilidades de emergencia de instancias de ruptura en las sociedades industrializadas se juegan, en parte, en la capacidad que tengan los procesos políticos tercermundistas para cortar el flujo de transferencias de los recursos económicos hacia el centro y de las crisis económicas hacia la periferia, que son condición de posibilidad de la expansión del confort en los centros. 
El propio desarrollo del subdesarrollo que produce la dinámica de la expansión capitalista en los países periféricos genera contradicciones que son específicas de este tipo de sociedades y que no se corresponden (o reproducen) linealmente en las economías desarrolladas. Estas contradicciones se relacionan con el problema de los "cuellos de botella" que encuentra el proceso de acumulación de capital y el progreso técnico en las sociedades subdesarrolladas a partir de la expansión de la dinámica capitalista y la industrialización de sus economías. Estos cuellos de botella, uno de los cuales (quizás el principal) es reconocido en la jerga como el momento de "estrangulamiento externo", tienen, como vimos en Marcuse, tres caminos para resolverse: acumulación originaria por medio de la inversión extranjera; o por medio de la dictadura que "sobreexplote" la fuerza del trabajo del país subdesarrollado; o, una tercera, de evidente inviabilidad histórica, que es la de la incorporación de los desarrollos técnicos en las economías subdesarrolladas a partir de sus propias tradiciones culturales, pero cuyo prerrequisito indispensable es el inverosímil abandono por parte de las grandes potencias occidentales y orientales del neocolonialismo.

Como vimos, Hinkelammert plantea también tres posibilidades de resolución del problema que se expresa en el estrangulamiento externo, pero lo mira desde el punto de vista de los actores de la propia sociedad subdesarrollada: una opción, entonces, es que las burguesías locales resuelvan las contradicciones que genera la expansión subdesarrollada del capitalismo en una alianza estrecha con inversiones extranjeras (devenir gerenciadores locales de las transnacionales), estrategia que, como comentamos, fue la que predominó entre las burguesías locales latinoamericanas; otra opción es la de las dictaduras fascistas desarrollistas, que fuerzan a las burguesías a seguir una vía de desarrollo capitalista relativamente autónoma y le garantizan a las mismas el disciplinamiento de las clases obreras para mantener la competitividad internacional de la fuerza local de trabajo (que, también como mencionamos, se expresó históricamente en las dictaduras de los años 60, como la de Onganía en Argentina y la que inicia Humberto de Alencar Castelo Branco en Brasil); y, por último, una que es la vía socialista, pero no al estilo burocrático soviético, sino un socialismo democrático. Es en esta última en la que se evidencia claramente la apuesta de los 
pueblos latinoamericanos por abrir el universo político en un camino diverso de los ofrecidos por los centros imperiales. Aquí encontramos una singularidad de la época y del propio teorizar latinoamericano.

En este punto, aparece nuevamente el problema del progreso técnicoeconómico asociado al desarrollo, y del que la sociedad de clases se había convertido en un apéndice. En nombre del progreso, el sistema es represivo, tal como afirma Marcuse (Fischetti 2015). En contra de la mistificación del consumo individual y del crecimiento económico, es posible vincular sensatamente al progreso técnico-económico con el desarrollo. Hinkelammert también propone pasos concretos que debe dar el socialismo latinoamericano para alcanzar el desarrollo, desde la democracia y la soberanía popular: la planificación estatal, la organización de las empresas fundamentales del país, la libertad de opinión, junto a un progreso técnico racional, negador de las mistificaciones.

En un contrapunto, en el mismo momento histórico y desde una perspectiva crítica común, hay una dialéctica que Marcuse y Hinkelammert comparten, la que tensiona el individuo y la sociedad, la ideología y la estructura. En esa tensión, sin embargo, notamos que, para Marcuse, las mediaciones principales son el trabajo y la racionalidad tecnológica (Fischetti 2012), y, en cambio, para Hinkelammert son el mercado y el Estado, instancias que organizan la división internacional del trabajo y el progreso técnico-económico. Marcuse señala, desde el Norte, una utopía que es históricamente inviable para el desarrollo autóctono en los países subdesarrollados, mientras que Hinkelammert plantea que, a partir de un empuje de política popular, hay una factibilidad histórica del desarrollo en América latina, según un modelo de socialismo democrático que tenga como horizonte la intervención sistemática de la soberanía popular sobre el Estado y el mercado, para evitar su fetichización e insistir en la afirmación de la primacía política del sujeto comunitario en la conducción del proceso histórico.

Tal como plantea Asselborn (2012 11-12), la crítica de Hinkelammert puede ser considerada una "crítica a la crítica", una crítica que, frente a utopías e idealizaciones de mundos en el que no rija ningún tipo de poder de clase, plantea la factibilidad histórica de sociedades gober- 
nadas por el poder político de base popular, democrática y socialista. Frente a críticas que corren el riesgo de tornarse conservadoras, por postular horizontes políticos idealizados, que no tienen raigambre en las correlaciones de fuerza reales, podemos afirmar que las luchas emancipatorias no se expresan en términos idealizados en América Latina, sino que han sido, son y seguirán siendo un insistente resurgir de los pueblos frente a la opresión.

\section{Bibliografía}

Arpini, Adriana María, coord. Otros discursos. Estudios de Historia de las ideas latinoamericanas. Mendoza: Facultad de Ciencias Políticas y Sociales, 2003.

Asselborn, Carlos Javier. "Necesidades, libertad y liberación", Polis [En línea] 28 (2011), Publicado el 15 abril 2012, consultado el 02 agosto 2016. URL: http://polis.revues.org/1323; DOI: 10.4000/polis.1323

Cardoso, Fernando y Faletto, E. Dependencia y desarrollo en América Latina. México: Siglo XXI, 1971.

Cooke, John William. Peronismo y Revolución. El peronismo y el Golpe de Estado: informe a las bases. Buenos Aires: Granica, 1973.

Cuervo Sola, Manuel. "Emancipación y vida: lo límites políticos del umbral teórico biopolítico". Revista de Filosofía 71/2 (2012): 7-22.

Fanon, Frantz. Los condenados de la tierra. Buenos Aires: Fondo de Cultura Económica, 2007.

Fernández Nadal, Estela. "Recepción de la Teoría Crítica en América latina: la constelación benjaminiana de marxismo y teología en Franz Hinkelammert", Franciscanum. Revista de Ciencias del Espíritu 54/158 (2012).

Fernández Nadal, Estela. "Humanismo, sujeto, modernidad. Sobre la crítica de la razón mítica de Franz Hinkelammert", ABRA, Revista de la Facultad de Ciencias Sociales 28/37-38 (2009).

Fernández Nadal, Estela. "Los estudios poscoloniales y la agenda de la filosofía latinoamericana actual", Revista Herramienta 24 (2004): 93-113

Fischetti, Natalia. "Psicoanálisis y marxismo. $\mathrm{O}$ de la dialéctica del trabajo y el deseo en la obra de Herbert Marcuse", La Actualidad de la Crítica. Ensayos sobre la Escuela de Frankfurt, ed. Nicolás del Valle, Nicolás. Santiago de Chile: Metales pesados, 2015. 175-206. 
Fischetti, Natalia. "Ciencia e ideología. Entrecruzamientos críticos en la obra de Herbert Marcuse". Contrastes, Revista Internacional de Filosofía XIX/1 (2014).

Fischetti, Natalia. "Un caleidoscopio-gran ola. Dialéctica de la racionalidad tecnológica en la obra de Herbert Marcuse". Revista Estudios. Filosofía práctica e historia de las ideas 13/14 (2012): 89-104.

Fischetti, Natalia y Cuervo, Manuel. "Experiencia, subjetividad y política. Preguntas sobre La cuestión humana en los contextos del nazismo y el neoliberalismo", Revista Agora philosophica. Revista marplatense de filosofía XII/24 (2011): 26-35.

Frigerio, Rogelio. Las condiciones de la victoria: Manual de política argentina. Buenos Aires: Sociedad Editora Argentina, 1959.

Frigerio, Rogelio. Crecimiento económico y democracia. Buenos Aires: Losada, 1963.

García Lupo, Rogelio. Mercenarios y monopolios en la Argentina: de Onganía a Lanusse, 1966-1971. Buenos Aires: Achaval Solo, 1971.

García Lupo, Rogelio. Contra la ocupación extranjera. Buenos Aires: Sudestada, 1968.

Hinkelammert, Franz. El subdesarrollo latinoamericano. Un caso de desarrollo capitalista. Buenos Aires: Paidós, 1970.

Hinkelammert, Franz. Las armas ideológicas de la muerte. San José de Costa Rica: EDUCA-DEI, 1977.

Jaguaribe, Helio. Desarrollo Económico y Desarrollo Político. Buenos Aires: EUDEBA, 1964.

Jaguaribe, Helio. Burguesía y Proletariado en el Nacionalismo Brasileño. Buenos Aires: Editorial Coyoacán, 1961.

Lander, Edgardo, comp. La colonialidad del saber: eurocentrismo y ciencias sociales. Perspectivas latinoamericanas. Buenos Aires: CLACSO, 2000.

Marcuse, Herbert. El hombre unidimensional. Ensayo sobre la ideología en la sociedad industrial avanzada. Barcelona: Ariel, 2010.

Marcuse, Herbert. El marxismo soviético. Un análisis crítico. Madrid: Revista de Occidente, 1967.

Marcuse, Herbert. La sociedad industrial y el marxismo. Buenos Aires: Quintaria, 1969. 
Prebisch, Raúl. "Crecimiento, desequilibrio y disparidades: interpretación del proceso de desarrollo económico", Estudio económico de América Latina, 1949. E/CN.12/164/Rev.1 (1950): 3-89.

Prebisch, Raul. "Interpretação do processo de desenvolvimento econômico da América Latina", Estudos Econômicos 1/3-4 (1950): 271-308.

Prebisch, Raúl. El desarrollo económico de la América Latina y algunos de sus principales problemas. NU-CEPA, 1949.

Roig, Arturo Andrés. El pensamiento latinoamericano y su aventura. Buenos Aires: El Andariego, 2008.

Roig, Arturo Andrés. Narrativa y cotidianidad. La obra de Vladimir Propp a la luz de un cuento ecuatoriano. Quito: Editorial Belén, 1984. 